\title{
A retrospective study on TS mRNA expression and prediction of the effects of adjuvant oral 5-fluorouracil in breast cancer
}

\author{
FUMINORI AKI $^{1}$, YOSHIMI BANDO ${ }^{1,2}$, TETSUYUKI TAKAHASHI ${ }^{1}$, HISANORI UEHARA ${ }^{1}$, \\ SATOSHI NUMOTO ${ }^{3}$, SUEYOSHI ITO ${ }^{4}$, MITSUNORI SASA ${ }^{5}$ and KEISUKE IZUMI ${ }^{1}$ \\ ${ }^{1}$ Department of Molecular and Environmental Pathology, Institute of Health Biosciences, \\ The University of Tokushima Graduate School, Tokushima 770-8503; ${ }^{2}$ Division of Pathology, \\ Tokushima University Hospital, Tokushima 770-8503; ${ }^{3}$ Kochi Health Sciences Center, Kouchi 781-8555; \\ ${ }^{4}$ Department of Surgery, Ito Surgical and Mammary Gland Clinic, Kouchi 780-0085; \\ ${ }^{5}$ Department of Surgery, Tokushima Breast Care Clinic, Tokushima 770-0052, Japan
}

Received June 30, 2010; Accepted September 2, 2010

DOI: $10.3892 / \mathrm{ol} .2010 .186$

\begin{abstract}
Nucleic acid-metabolizing enzymes, such as thymidylate synthase (TS), dihydropyrimidine dehydrogenase (DPD), thymidine phosphorylase (TP) and orotate phosphoribosyl transferase (OPRT), have attracted attention as candidates for response determinants of 5-fluorouracil (5-FU). Whether the expression levels of these enzymes can be adopted as valuable parameters for 5-FU sensitivity in breast cancer has yet to be elucidated. In the present study, intratumoral mRNA expression of TS, DPD, TP and OPRT were determined in formalin-fixed paraffin-embedded surgical specimens collected from 217 breast cancer patients, using the Danenberg Tumor Profile method, which combines microdissection and real-time-polymerase chain reaction. The significance of these enzymes as prognostic and 5-FU efficacy-predicting factors was evaluated. Our data showed that a low DPD expression is related to a high nuclear grade and other factors including hormone receptor-negativity. Low expression levels of TP were found in hormone receptornegative tumors. TS and OPRT expression were not related to various clinicopathological factors, but patients with a high TS mRNA expression showed a significantly poorer prognosis in cases where 5-FU was not administered. The efficacy of 5-FU was more significant when administered for more than 6 months in the group with a high TS mRNA expression. These data suggest that TS mRNA expression in breast cancer tissue is an ideal predictor of outcomes for patients with no administration of 5-FU, and of the efficacy of 5-FU.
\end{abstract}

Correspondence to: Dr Yoshimi Bando, Division of Pathology, Tokushima University Hospital, 2-50-1 Kuramoto-Cho, Tokushima 770-8503, Japan

E-mail: yoshimi@basic.med.tokushima-u.ac.jp

Key words: thymidylate synthase, breast cancer, 5-fluorouracil, real-time polymerase chain reaction

\section{Introduction}

Modalities such as endocrine therapy, chemotherapy and therapy using antibodies are widely used for early operable breast cancer to prevent relapse after surgery. The guidelines established at the St. Gallen Consensus Conference (1) propose therapeutic approaches based on treatment thresholds that are stratified by hormone receptor expression [including estrogen receptors (ER) and progesterone receptors (PgR)] and HER-2 overexpression or amplification (1). Moreover, it is crucial to use chemotherapy for any patient with breast cancer without these targets, but with a high risk of recurrence, even if patient results are positive for hormone receptors. Chemotherapy is a therapeutic option for patients with recurrence risks, notably those with early-stage disease. However, no specific markers exist to forecast the effectiveness of anti-cancer drugs.

In recent studies on prognostic factors and factors predicting the effects of chemotherapy, enzymes such as thymidylate synthase (TS), dihydropyrimidine dehydrogenase (DPD), thymidine phosphorylase (TP) and orotate phosphoribosyl transferase (OPRT) have shown notable effects on 5-FU as a chemotherapeutic agent. These studies have mainly focused on cancers of the digestive system (2-9).

TS is a target enzyme for chemotherapy with 5-fluorouracil (5-FU). Numerous studies have found that 5-FU therapy for metastatic and advanced colon cancer is more effective in patients with low levels of intratumoral TS mRNA or TS protein expression compared to patients with high levels of expression (2-6). However, certain studies report that 5-FU post-operative adjuvant chemotherapy is effective in patients with colon cancers expressing high TS levels (7-9). Attention has been focused on 5-FU therapy and TS expression levels in breast cancer. Patients with breast cancers that express low TS levels and who receive 5-FU-based chemotherapy have an ideal prognosis $(10,11)$. However, the addition of tegafur-uracil (UFT), an oral 5-FU agent, to hormone monotherapy given as post-operative adjuvant therapy for breast cancer is likely to offer longer relapse-free survival (RFS) time in patients with high levels of TS expression (12). 
DPD is a 5-FU degrading enzyme. It has been reported that 5-FU therapy for advanced head and neck cancers is more effective in patients with lower ratios of tumor/non-tumor DPD enzymatic activities (13). Another study on adjuvant chemotherapy following surgery for breast cancer also showed 5-FU to be associated with more a favorable prognosis in patients with lower DPD expression (14).

TP, also known as platelet-derived endothelial cell growth factor, appears to behave in a manner similar to TS. In metastatic colon cancer, 5-FU therapy is less effective for patients with high levels of intratumoral TP mRNA expression (15). Alternatively, TP expression was mainly observed in the tumor stroma of colorectal carcinoma, where patients with a high TP expression showed a more favorable prognosis and a lower rate of metastasis than patients with a low TP expression (16).

OPRT is a phosphorylating enzyme of 5-FU. OPRT activity in tumor tissue is reportedly related to prognosis and 5-FU sensitivity in colon cancer (17-19).

Additionally, whether these molecular markers predict 5-FU efficacy in breast cancer is controversial, since the histological variety of breast cancer specimens contains large amounts of cancerous stroma and non-tumorous tissues. Gene expression levels of TS, DPD and TP in carcinoma cells and stroma were shown to vary in breast cancer (20). Laser capture microdissection (LCM) and real-time polymerase chain reaction (RT-PCR) are effective techniques for measuring gene expression in carcinoma cells. However, few reports exist regarding the expression of these enzymes in breast carcinoma cells analyzed by LCM plus RT-PCR in association with the prognosis and effect of 5-FU.

In this study, a retrospective approach was adopted to investigate whether markers such as intratumoral TS, DPD, TP and OPRT analyzed by LCM plus RT-PCR in formalin-fixed paraffin-embedded specimens may be used as prognostic or sensitivity-defining factors (5-FU efficacy-determining factors).

\section{Materials and methods}

Case series. A total of 217 patients who had undergone surgery between 1988 and 2006 at Ito Surgical Mammary Gland Clinic and Tokushima Breast Care Clinic, Japan, for primary breast cancer were recruited. The median duration of observation was 7.6 years. This study was approved by the Ethics Committee of the Tokushima University Hospital and the patients gave written consent. Patient characteristics and stage grouping corresponding to pTNM categories by UICC are shown in Table I. Oral 5-FU agents were administered to 147 patients, of whom 127 were able to continue the medication for $\geq 6$ months. UFT, doxifluridine (5'-DFUR) and 5-FU tablets were used as oral 5-FU agents. A total of 20 patients stayed on the medication for $<6$ months. A total of 70 patients did not receive any oral 5-FU agents. Postoperative endocrine therapy was carried out in 112 cases.

Determination of gene expression levels related to 5-FUmetabolizing enzymes using RT-PCR. Following the evaluation of hematoxylin-eosin-stained slides by pathologists, 5 slides of $5-\mu \mathrm{m}$ sections were prepared from each formalin-fixed paraffin-embedded specimen. The Danenberg Tumor Profile (DTP) method (Response Genetics, Inc., Los Angeles, CA,
Table I. Patient characteristics.

\begin{tabular}{lr}
\hline No. of patients & 217 \\
Age & \\
Median & 53 \\
Range & $24-83$ \\
Stage & \\
I & 109 \\
II & 88 \\
III & 20 \\
Menopausal status & \\
Premenopausal & 85 \\
Postmenopausal & 132 \\
Histological classification & \\
Papillotubular carcinoma & 64 \\
Solid-tubular carcinoma & 24 \\
Scirrhous carcinoma & 96 \\
Mucinous carcinoma & 6 \\
Medullary carcinoma & 10 \\
Others & 17
\end{tabular}

ER

$\begin{array}{ll}- & 61\end{array}$

$\begin{array}{ll}- & 147\end{array}$

$\operatorname{PgR}$

$\begin{array}{lr}- & 83\end{array}$

$\begin{array}{lr}+ & 125\end{array}$

HER-2

$0,1 \quad 136$

223

324

Axillary lymph node metastasis

- $\quad 141$

$+\quad 73$

Nuclear grade

$1 \quad 109$

2218

3235

Hormonal therapy

Not received 105

Received 112

Chemotherapy of oral 5-FU

Not received 70

Received ( $<6$ months) $\quad 20$

Received ( $\geq 6$ months) $\quad 127$

USA, United States Patent Number 6,248,535), a system combining LCM technique and quantitative RT-PCR through Taq Man (Applied Biosystems) chemistry, was employed to measure quantities of mRNA for nucleic acid-metabolizing enzymes in tumor tissues on the slides. Following RNA extraction, the cDNA was prepared as previously described (21). The sequence of the target cDNA was amplified using 
Table II. Association of TS, DPD, TP and OPRT mRNA expression with various clinicopathological factors.

\begin{tabular}{|c|c|c|c|c|c|c|c|c|}
\hline mRNA (mean) & TS & P-value & DPD & P-value & ТP & P-value & OPRT & P-value \\
\hline Stage & & NS & & $<0.05$ & & NS & & NS \\
\hline I & 3.72 & & 1.79 & & 14.3 & & 1.57 & \\
\hline II & 3.24 & & 1.39 & & 14.5 & & 1.54 & \\
\hline III & 4.07 & & 1.74 & & 12.8 & & 1.84 & \\
\hline Menopausal status & & NS & & $<0.05$ & & NS & & NS \\
\hline Premenopausal & 3.88 & & 1.82 & & 12.2 & & 1.63 & \\
\hline Postmenopausal & 3.33 & & 1.48 & & 15.5 & & 1.55 & \\
\hline Axillary lymph node metastasis & & NS & & NS & & $<0.05$ & & NS \\
\hline- & 3.58 & & 1.69 & & 15.5 & & 1.58 & \\
\hline+ & 3.45 & & 1.44 & & 11.7 & & 1.55 & \\
\hline Nuclear grade & & NS & & $<0.01$ & & NS & & NS \\
\hline 1 & 3.34 & & 1.73 & & 13.9 & & 1.61 & \\
\hline 2 & 3.93 & & 1.63 & & 14.6 & & 1.47 & \\
\hline 3 & 4.10 & & 1.25 & & 15.4 & & 1.56 & \\
\hline Histological classification & & NS & & $<0.05$ & & NS & & NS \\
\hline Papillotubular carcinoma & 3.26 & & 1.51 & & 12.7 & & 1.65 & \\
\hline Scirrhous carcinoma & 3.39 & & 1.71 & & 13.7 & & 1.36 & \\
\hline ER & & NS & & $<0.01$ & & $<0.01$ & & NS \\
\hline- & 3.62 & & 1.28 & & 12.7 & & 1.47 & \\
\hline+ & 3.55 & & 1.76 & & 15.0 & & 1.63 & \\
\hline PgR & & NS & & $<0.01$ & & $<0.05$ & & NS \\
\hline- & 3.55 & & 1.37 & & 13.4 & & 1.48 & \\
\hline+ & 3.58 & & 1.78 & & 15.0 & & 1.66 & \\
\hline HER-2 & & NS & & NS & & NS & & NS \\
\hline 0,1 & 3.66 & & 1.63 & & 13.7 & & 1.61 & \\
\hline 2 & 3.76 & & 1.70 & & 17.2 & & 1.84 & \\
\hline 3 & 2.93 & & 1.51 & & 15.2 & & 1.23 & \\
\hline
\end{tabular}

The mean value of the ratio to the expression of the $\beta$-actin of each mRNA is shown. Student's t-test (comparison between two groups) or ANOVA (comparison between three groups) was used to test the difference between $\log _{10}$ (mean) of the subgroups. TS, thymidylate synthase; DPD, dihydropyrimidine dehydrogenase; TP, thymidine phosphorylase and OPRT, orotate phosphoribosyl transferase.

RT-PCR by the Taq Man method [ABI PRISM 7900 Sequence Detection System (Taq Man); Applied Biosystems, Foster City, CA, USA]. The PCR reaction mixture contained the primers: dATP, dCTP, dGTP, dUTP, $\mathrm{MgCl}_{2}$ and Taq Man buffer (reagents from Applied Biosystems). PCR conditions were $10 \mathrm{sec}$ at $50^{\circ} \mathrm{C} ; 10 \mathrm{~min}$ at $95^{\circ} \mathrm{C}$, followed by 42 reaction cycles (each cycle lasting $15 \mathrm{sec}$ at $95^{\circ} \mathrm{C}$ and $1 \mathrm{~min}$ at $60^{\circ} \mathrm{C}$ ). Each mRNA expression level was computed from its ratio to the expression of $\beta$-actin.

Immunohistochemical analysis. Immunohistochemical analysis for ER, PgR and HER-2 was performed on the patients. Positive responses to ER or PgR were determined when $\geq 10 \%$ of the tumor tissues were stained. HER-2 responses were classified into four levels (0-3) based on the HercepTest: 0, no staining; $1+$, weak partial membranous staining in $\geq 10 \%$ of cells; $2+$, weak to moderate complete membranous staining in $\geq 10 \%$ of cells and $3+$, strong complete membranous staining in $\geq 10 \%$ of cells.
Statistical analysis. mRNA expression levels of each enzyme were converted into the value for $\log _{10}$ (mRNA) and the values were assessed using the Student's t-test (two-sided) or ANOVA. Univariate and multivariate survival analyses based on Cox's proportional hazard regression model were used to evaluate independent contributions of each variable to RFS for 70 patients not treated with 5-FU. The appropriate cut-off value for each mRNA was calculated using receiver operating characteristic (ROC) analysis. Sensitivity and specificity were computed from relationships with each mRNA, designating relapse as positive and relapse-free states as negative. Factors were investigated in the 127 patients who were on 5-FU agents for $\geq 6$ months to predict the efficacy, based on the cut-off value obtained through ROC analysis. The patients were divided into a low or high group, using the cut-off values of each mRNA. An estimate of RFS was calculated using the Kaplan-Meier method, and differences were assessed using the log-rank test. RFS was analyzed between patients who received 5 -FU for $\geq 6$ months and those who received it 
Table III. Univariate and multivariate analysis of clinicopathological factors and mRNA expression.

\begin{tabular}{|c|c|c|c|c|}
\hline \multirow[t]{2}{*}{ Prognostic factor } & \multicolumn{2}{|c|}{ Univariate analysis } & \multicolumn{2}{|c|}{ Multivariate analysis } \\
\hline & Hazard ratio & P-value & Hazard ratio & P-value \\
\hline Stage & & NS & & \\
\hline I & 1 & & & \\
\hline II, III & 0.91 & & & \\
\hline Menopausal status & & NS & & \\
\hline Premenopausal & 1 & & & \\
\hline Postmenopausal & 1.30 & & & \\
\hline Axillary lymph node metastasis & & NS & & $<0.05$ \\
\hline- & 1 & & 1 & \\
\hline+ & 3.18 & & 11.6 & \\
\hline Nuclear grade & & $<0.05$ & & $<0.05$ \\
\hline 1,2 & 1 & & 1 & \\
\hline 3 & 5.38 & & 6.12 & \\
\hline Histological classification & & NS & & \\
\hline Papillotubular carcinoma & 1 & & & \\
\hline Scirrhous carcinoma & 0.76 & & & \\
\hline ER & & NS & & \\
\hline- & 1 & & & \\
\hline+ & 0.81 & & & \\
\hline Pgr & & NS & & \\
\hline- & 1 & & & \\
\hline+ & 0.91 & & & \\
\hline HER-2 & & NS & & \\
\hline 0,1 & 1 & & & \\
\hline 2,3 & 1.02 & & & \\
\hline TS & & $<0.01$ & & $<0.01$ \\
\hline Low $(<4.57)$ & 1 & & 1 & \\
\hline High $(\geq 4.57)$ & 6.67 & & 10.9 & \\
\hline DPD & & NS & & \\
\hline Low $(<1.8)$ & 1 & & & \\
\hline $\operatorname{High}(\geq 1.8)$ & 0.66 & & & \\
\hline TP & & NS & & \\
\hline Low $(<11.8)$ & 1 & & & \\
\hline $\operatorname{High}(\geq 11.8)$ & 1.78 & & & \\
\hline OPRT & & NS & & \\
\hline Low $(<1.66)$ & 1 & & & \\
\hline High $(\geq 1.66)$ & 3.56 & & & \\
\hline
\end{tabular}

TS, thymidylate synthase; DPD, dihydropyrimidine dehydrogenase; TP, thymidine phosphorylase and OPRT, orotate phosphoribosyl transferase; NS, not significant.

for $<6$ months or not at all. 5-FU may not have exhibited an adequate effect in the 20 patients who had discontinued it after less than 6 months due to factors including adverse events (10 patients) and patient refusal (5 patients). Significance was set at $\mathrm{P}<0.05$. JMP ver7.0.1, provided by SAS Institute, Inc., was used for the statistical analysis. As the event number was small, overall survival (OS) was not calculated.

\section{Results}

Evaluation of mRNA expression levels and correlation to clinicopathological factors. The expression of mRNA in breast cancer was successfully determined in 166, 172, 174 and 167 patients, and the median mRNA expression levels were 3.05, 1.35, 11.9 and 1.39 for TS, DPD, TP and OPRT, respectively. 


\section{A No administration of 5-FU}

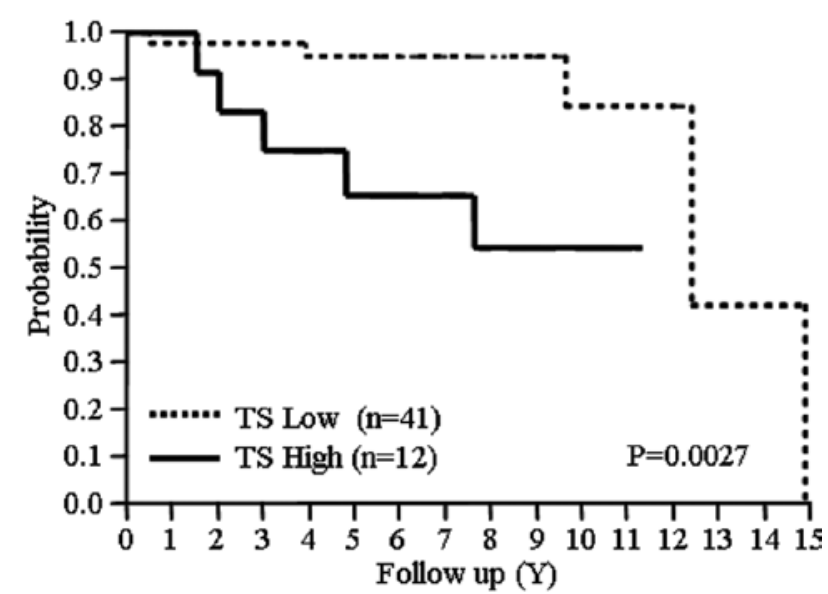

B TS Low group

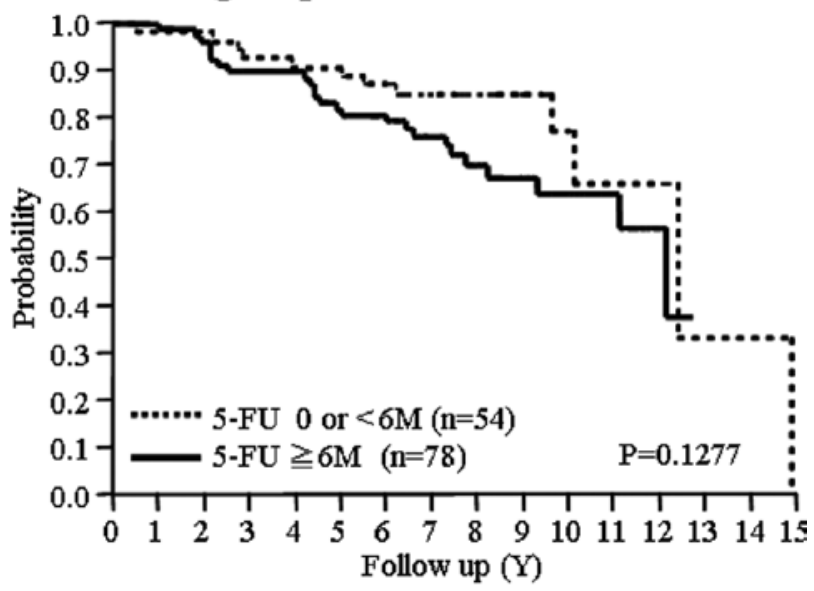

\section{TS High group}

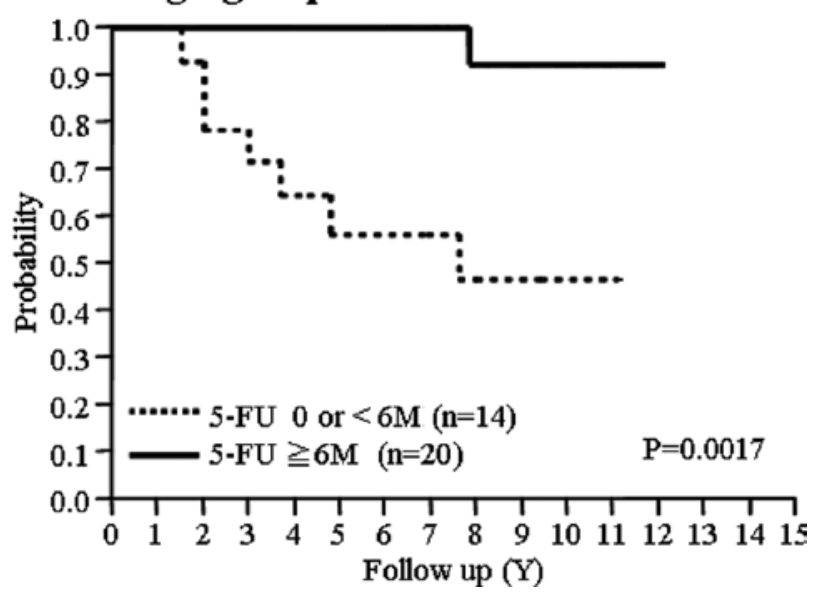

Figure 1. Relationship between relapse-free survival (RFS) and TS mRNA expression, and between RFS and TS mRNA expression in patients with no administration of 5-FU is shown. (A) Patients were divided into two groups with a low $(\mathrm{TS}<4.57)$ versus a high $(\mathrm{TS} \geq 4.57) \mathrm{TS}$ expression. Correlation of RFS to 5-FU administration in (B) the TS-low and (C) TS-high groups. Each group was divided into two groups: patients who received no administration of 5-FU or had taken it for $<6$ months, and patients who received 5-FU for $\geq 6$ months.

The results failed to indicate any correlation between TS and OPRT expression and various clinicopathological factors (Table II). DPD expression was reduced, and inversely related to the nuclear grade. A low DPD expression was detected in postmenopausal patients and in hormone receptor-negative tumors. A low TP expression was detected in patients with lymph node metastasis and with hormone receptor-negative tumors.

Correlation between mRNA expression levels and RFS in patients without 5-FU agents. Univariate analysis focusing on RFS showed the nuclear grade and TS expression level to be significant prognostic factors. Multivariate analysis identified the presence (or absence) of axillary lymph node metastases, nuclear grade and the TS expression level as independent prognostic factors for RFS (Table III).

TS expression level as prognostic factor, predicting the effect of 5-FU agents. The prognosis was significantly better in the low TS group where no 5-FU was administered (Fig. 1A). In addition, prognosis of the low TP group was significantly better, but no correlation was found between DPD or OPRT expression levels and RFS time (data not shown). No difference was noted between patients who received 5-FU administration for $\geq 6$ months and those who had $<6$ months or none in the low TS group, while the high TS group showed a significantly more favorable prognosis when 5-FU was administered for 6 months or more (Fig. 1B and C). No differences were found on completion of similar analyses for DPD, TP and OPRT to that of TS (data not shown).

\section{Discussion}

This study presented novel information regarding correlations between TS mRNA expression and prognosis in 217 breast cancer patients. Part of our data was included in the results of a recent report on a large number of test subjects with regard to TS, DPD and OPRT mRNA and protein expression levels in certain tumors (22).

Positive TS immunoreactivity in breast cancer tissue is associated with aggressive phenotypes, including large tumor size, high histological grade and nodal metastasis (10). Failure to correlate TS mRNA expression with clinicopathological factors in the present study may be due to variations in the methods regarding detection and evaluations. Results of the multivariate analysis suggest that the TS mRNA expression level was an independent factor.

Observation of the RFS time stratified by the level of TS mRNA suggest that TS is an effective prognostic factor for patients that did not receive 5-FU. These results suggest a favorable prognosis in patients whose level of TS mRNA expression is less than 4.57, while the effect of oral 5-FU is believed to be minimal. Among patients with TS mRNA levels exceeding 4.57 , on the other hand, the prognosis was relatively poor. Such patients may require an alternative form of treatment.

Factors that predict the efficacy of oral 5-FU agents showed their recurrence-preventing effects, particularly in patients expressing TS mRNA levels of 4.57 or more. The findings of this study coincide with other findings, including the effect of an oral 5-FU agent (UFT) on hormone monotherapy applied as postoperative adjuvant therapy for breast cancer (12), and longer RFS time in the group with a high TS expression, as examined by immunohistochemistry.

Therapies using infusional 5-FU, such as CMF (cyclophosphamide, methotrexate and fluorouracil) and $\mathrm{CEF}$ 
(cyclophosphamide, epirubicin and fluorouracil) regimens, have resulted in a favorable prognosis for patients with low TS cancers $(10,11)$. Our data, however, were not in agreement with these results. Oral administration of 5-FU showed a higher peak level in blood than did continuous intravenous injection of 5-FU at an equal molar ratio (23). The reliability of TS as a predictor for 5-FU efficacy may thus differ between oral and infusional 5-FU.

The estimation of TS mRNA expression by microdissection and RT-PCR from formalin-fixed paraffin-embedded specimens may be more useful than immunohistochemistry, as cut-off values are clearly calculated. We calculated a useful cut-off value and patient ratio for prognostic predictions and 5-FU effect forecast using ROC analysis. This study showed that the proportion of cases expressing high TS levels was as much as $20 \%$ of all patients. Such patients are expected to achieve a high relapse prevention effect following oral 5-FU administration for 6 months or more as postoperative adjuvant chemotherapy. Pestalozzi et al analyzed TS expression in early breast cancer by immunohistochemistry and reported that node-negative patients with high TS levels showed a significant improvement in disease-free survival and OS when treated with six cycles of adjuvant CMF therapy, compared with those receiving only one cycle (24). Our result coincided with this report, suggesting that completion of chemotherapy leads to a favorable prognosis.

In this study, high DPD or TP levels in breast cancer tissue correlated with a positive expression of hormone receptors. These results imply that UFT including the DPD inhibitor is efficacious as an oral 5-FU derivative for the hormone receptor-positive patient.

The present study found prognostic value only in the expression of TS and TP, and an efficacy-predicting value in TS expression. However, other investigators showed the expression of DPD, TP or OPRT to be correlated with various clinicopathological factors, prognosis and efficacy of 5-FU agents (14,25-28). Although the reason for these discrepancies was unclear, trials to verify prognosis and efficacy of the 5-FU agents while taking clinicopathological factors into account are a crucial strategic objective to further validate useful biomarkers.

In conclusion, TS mRNA is effective for breast cancer prognosis and as a predictor of efficacy for oral 5-FU anticancer agents among the mRNA expression of 5-FU-metabolizing enzymes. Thresholds for systemic treatment modality indications were discussed in St. Gallen (1), and those for cytotoxic chemotherapy use have yet to be clearly defined. Increasingly, greater expectation is to be placed on the use of individualized medicine, using prognostic and efficacy-predicting markers. If TS mRNA expression levels can be utilized in this manner, more selective and efficacious treatments may become possible. Our results were obtained with short follow-up times in a small-scale population analysis. Larger-scale studies are required in prospective clinical trials for patients with breast cancer before using TS expression as a predictive factor.

\section{Acknowledgements}

This study was partially supported by a Grant-in Aid from Taiho Pharmaceutical Co., Cancer Research, Japan. We also thank Ms. Kume, Ms. Umemoto and Ms. Takai for their technical assistance.

\section{References}

1. Goldhirsch A, Ingle JN, Gelber RD, Coates AS, Thürlimann B and Senn HJ (Panel members): Thresholds for therapies: highlights of the St Gallen International Expert Consensus on the primary therapy of early breast cancer 2009. Ann Oncol 20: 1319-1329, 2009.

2. Bathe OF, Franceschi D, Livingstone AS, Moffat FL, Tian E and Ardalan B: Increased thymidylate synthase gene expression in liver metastases from colorectal carcinoma: implications for chemotherapeutic options and survival. Cancer J Sci Am 5: 34-40, 1999.

3. Cascinu S, Aschele C, Barni S, Debernardis D, Baldo C, Tunesi G, Catalano V, Staccioli MP, Brenna A, Muretto P and Catalano G: Thymidylate synthase protein expression in advanced colon cancer: correlation with the site of metastasis and the clinical response to leucovorin-modulated bolus 5-fluorouracil. Clin Cancer Res 5: 1996-1999, 1999.

4. Leichman CG, Lenz HJ, Leichman L, Danenberg K, Baranda J, Groshen S, Boswell W, Metzger R, Tan M and Danenberg PV: Quantitation of intratumoral thymidylate synthase expression predicts for disseminated colorectal cancer response and resistance to protracted-infusion fluorouracil and weekly leucovorin. J Clin Oncol 15: 3223-3229, 1997.

5. Lenz HJ, Hayashi K, Salonga D, Danenberg KD, Danenberg PV, Metzger R, Banerjee D, Bertino JR, Groshen S, Leichman LP and Leichman CG: p53 point mutations and thymidylate synthase messenger RNA levels in disseminated colorectal cancer: an analysis of response and survival. Clin Cancer Res 4: 1243-1250, 1998.

6. Paradiso A, Simone G, Petroni S, Leone B, Vallejo C, Lacava J, Romero A, Machiavelli M, De Lena M, Allegra CJ and Johnston PG: Thymidilate synthase and p53 primary tumour expression as predictive factors for advanced colorectal cancer patients. Br J Cancer 82: 560-567, 2000.

7. Edler D, Glimelius B, Hallström M, Jakobsen A, Johnston PG, Magnusson I, Ragnhammar P and Blomgren H: Thymidylate synthase expression in colorectal cancer: a prognostic and predictive marker of benefit from adjuvant fluorouracil-based chemotherapy. J Clin Oncol 20: 1721-1228, 2002.

8. Johnston PG, Fisher ER, Rockette HE, Fisher B, Wolmark N, Drake JC, Chabner BA and Allegra CJ: The role of thymidylate synthase expression in prognosis and outcome of adjuvant chemotherapy in patients with rectal cancer. J Clin Oncol 12: 2640-2647, 1994.

9. Takenoue T, Nagawa H, Matsuda K, Fujii S, Nita ME, Hatano K, Kitayama J, Tsuruo T and Muto T: Relation between thymidylate synthase expression and survival in colon carcinoma, and determination of appropriate application of 5-fluorouracil by immunohistochemical method. Ann Surg Oncol 7: 193-198, 2000.

10. Yu Z, Sun J, Zhen J, Zhang Q and Yang Q: Thymidylate synthase predicts for clinical outcome in invasive breast cancer. Histol Histopathol 20: 871-878, 2005.

11. Hakamada Y, Tsuchida A, Arima M, Kubouchi T, Tokita H, Ota D, Kaise H, Aoki T, Kusama M and Aoki T: Prognostic predictors in breast cancer patients with postoperative 5-fluorouracil-based chemotherapy. Int J Mol Med 16: 309-314, 2005.

12. Toi M, Ikeda T, Akiyama F, Kurosumi M, Tsuda H, Sakamoto G and Abe O: Predictive implications of nucleoside metabolizing enzymes in premenopausal women with node-positive primary breast cancer who were randomly assigned to receive tamoxifen alone or tamoxifen plus tegafur-uracil as adjuvant therapy. Int $\mathrm{J}$ Oncol 31: 899-906, 2007.

13. Etienne MC, Chéradame S, Fischel JL, Formento P, Dassonville O, Renée N, Schneider M, Thyss A, Demard F and Milano G: Response to fluorouracil therapy in cancer patients: the role of tumoral dihydropyrimidine dehydrogenase activity. J Clin Oncol 13: 1663-1670, 1995.

14. Horiguchi J, Yoshida T, Koibuchi Y, Iijima K, Ninomiya J, Takei H, Yokoe T, Iino Y and Morishita Y: DPD activity and immunohistochemical DPD expression in human breast cancer. Oncol Rep 11: 65-72, 2004. 
15. Metzger R, Danenberg K, Leichman CG, Salonga D, Schwartz EL, Wadler S, Lenz HJ, Groshen S, Leichman L and Danenberg PV: High basal level gene expression of thymidine phosphorylase (platelet-derived endothelial cell growth factor) in colorectal tumors is associated with nonresponse to 5-fluorouracil. Clin Cancer Res 4: 2371-2376, 1998.

16. Saito S, Tsuno N, Nagawa H, Sunami E, Zhengxi J, Osada T, Kitayama J, Shibata Y, Tsuruo T and Muto T: Expression of platelet-derived endothelial cell growth factor correlates with good prognosis in patients with colorectal carcinoma. Cancer 88: 42-49, 2000

17. Ochiai T, Sugitani M, Nishimura K, Noguchi H, Watanabe T, Sengoku H, Komiyama $\mathrm{H}$ and Okano M: Correlation between clinical pathophysiologic factors and expression of orotate phosphoribosyl transferase (OPRT), thymidylate synthase (TS), and dihydropyrimidine dehydrogenase (DPD) in colorectal cancer (in Japanese). Gan To Kagaku Ryoho 29: 413-420, 2002.

18. Ochiai T, Nishimura K, Noguchi H, Kitajima M, Tsukada A Watanabe E, Nagaoka I and Futagawa S: Prognostic impact of orotate phosphoribosyl transferase among 5-fluorouracil metabolic enzymes in resectable colorectal cancers treated by oral 5-fluorouracil-based adjuvant chemotherapy. Int J Cancer 118: 3084-3088, 2006.

19. Ichikawa W, Uetake H, Shirota Y, Yamada H, Takahashi T, Nihei Z, Sugihara K, Sasaki Y and Hirayama RK: Both gene expression for orotate phosphoribosyltransferase and its ratio to dihydropyrimidine dehydrogenase influence outcome following fluoropyrimidine-based chemotherapy for metastatic colorectal cancer. Br J Cancer 89: 1486-1492, 2003.

20. Kakimoto M, Uetake H, Osanai T, Shirota Y, Takagi Y, Takeshita E, Toriya Y, Danenberg K, Danenberg PV and Sugihara K: Thymidylate synthase and dihydropyrimidine dehydrogenase gene expression in breast cancer predicts 5-FU sensitivity by a histocultural drug sensitivity test. Cancer Lett 223: 103-111, 2005.
21. Makino H, Uetake H, Danenberg KD, Danenberg PV and Sugihara K: Efficacy of laser capture microdissection plus RT-PCR technique in analyzing gene expression levels in human gastric cancer and colon cancer. BMC Cancer 8: 210, 2008.

22. Fukui Y, Oka T, Nagayama S, Danenberg PV, Danenberg KD and Fukushima M: Thymidylate synthase, dihydropyrimidine dehydrogenase, orotate phosphoribosyltransferase mRNA and protein expression levels in solid tumors in large scale population analysis. Int J Mol Med 22: 709-716, 2008.

23. Ho DH, Pazdur R, Covington W, Brown N, Huo YY, Lassere Y and Kuritani J: Comparison of 5-fluorouracil pharmacokinetics in patients receiving continuous 5-fluorouracil infusion and oral uracil plus N1-(2'-tetrahydrofuryl)-5-fluorouracil. Clin Cancer Res 4: 2085-2088, 1998

24. Pestalozzi BC, Peterson HF, Gelber RD, et al: Prognostic importance of thymidylate synthase expression in early breast cancer. J Clin Oncol 15: 1923-1931, 1997.

25. Kurebayashi J, Yamamoto Y, Udagawa K, Okubo S, Fukushima M and Sonoo H: Establishment of enzyme-linked immunosorbent assays for thymidylate synthase and dihydropyriminide dehydrogenase in cancer tissues. Oncol Rep 11: 973-979, 2004.

26. Ioachim E: Thymidine phoshorylase expression in breast cancer: the prognostic significance and its association with other angiogenesis related proteins and extracellular matrix components. Histol Histopathol 23: 187-196, 2008.

27. Bronckaers A, Gago F, Balzarini J and Liekens S: The dual role of thymidine phosphorylase in cancer development and chemotherapy. Med Res Rev 29: 903-953, 2009.

28. Tsunoda Y, Suzuki K, Sakamoto MA, Date Y, Sawada T, Tsunoda A and Kusano M: Evaluation of 5-fluorouracil-related genes in breast cancer to predict the effect of adjuvant therapy with CMF (in Japanese). Gan To Kagaku Ryoho 36: 51-55, 2009. 